out-patient basis. Examples of suitable procedures are shown in Table II.

Examples of procedures that are inappropriate for outpatient management are situations where blood transfusion is likely to be necessary, where physiologic or emotional disturbance of the patient might ensue or where postoperative surgical care might be complicated. Anything requiring the patient to be immobilised for long periods is unsuitable. Postoperative pain management must also be a consideration because only oral medications will be available.

The duration of the surgery is commonly limited to less than 90 minutes; however, longer cases are very regularly performed on an outpatient basis for example restorative dentistry. However, the longer the surgical procedure the greater the care that must be exercised regarding all phases of postoperative management.
In conclusion, almost every procedure that does not require the patient's admission for surgical reasons can from the anaesthetist's viewpoint be done satisfactorily on an outpatient basis. The increasing capability of anaesthetic management made possible by advances in pharmacology, monitoring technology, clinical skills and careful cooperation between surgeon and anaesthetist has made the surgery, social circumstances, and domicile of the patient the major limiting factors when patients for day care surgery are being selected. Dedication to patient safety must be the goal of all outpatient surgical programs. An essential step toward this goal is collaboration between surgeons and anaesthetists regarding preoperative assessment, appropriate surgery, and final sclcction of patients suitable for day care surgery. The second step is strict observance of those principles that have been established.

\title{
General anaesthesia for day care surgery patients
}

Robert B. Forbes MD

General anaesthesia for day care surgery requires the same basic equipment for anaesthesia delivery, monitoring and resuscitation as is necessary for inpatients. Similarly, there must be appropriately designed preparation and recovery areas. Staff must be properly trained; and from that staff a team capable of providing advanced cardiopulmonary resuscitation, whenever required, must be made available. If the unit is free standing, arrangements must be made for maintenance of equipment. The selection of patients for day care surgery is described elsewhere.

A preoperative visit by the anaesthetist should do much to allay anxiety. Short-acting sedatives and narcotic analgesics are welcomed by some patients. In general, though, the unpleasant side effects of pre-medication far outweigh their benefits. In colder climates it is worth making an effort to ensure that patients are warm when they come to the operating room, thereby making venipuncture easter. Premedication with atropine or glycopyrrolate is unnecessary except perhaps for some small children or infants. In our experience, the incidence of postoperative nausea and vomiting is small, but patients with a history of nausea may benefit from the use of an anti-emetic as pre-medication ${ }^{1}$ or intravenously at the termination of surgery. ${ }^{2}$

An important objective for the anaesthetist is that the patient becomes "street-fit" as soon as possible following surgery. All inhalation techniques and intravenous drugs appropriate for inpatients can be used successfully for outpatients. Recent studies ${ }^{3,4}$ of psychomotor function following anaesthesia with fentanyl, enflurane and isoflurane revealed

Robert B. Forbes, MD, Clinical Lecturer, University of Alberta. Department of Anaesthesia, Charles Camsell General Hospital, Edmonton, Alberta. 
only small, clinically insignificant differences in visualization, response time and arousal state scores in the early postoperative period.

Whatever technique is selected the anaesthetist must adjust the duration of administration and dosage of the anaesthetic agent to facilitate rapid recovery. However, the risk of the patient being aware during surgery must not be forgotten. When an inhalation technique has been chosen and a closed circuit carbon dioxide absorber system is used, it is usually possible to turn off the fresh gas flow of nitrous oxide and halogenated agent about fifteen minutes prior to the completion of surgery for each hour of anaesthetic administration. ${ }^{5}$

An ideal anaesthetic agent should produce loss of consciousness rapidly and pleasantly, result in little cardiorespiratory disturbance and possess no serious side effects. A variety of intravenous agents have been used for the induction or maintenance of anaesthesia in day care surgery including thiopental, alfentanil, propanadid, ketamine, althesin, diazepam, midazolam and etomidate. ${ }^{6-8}$ None of these medications can be considered an ideal agent.

Thiopental, the most widely used induction agent, is a cardiovascular depressant that frequently causes hypotension, often followed by severe hypertension and tachycardia during tracheal intubation. These transient changes in cardiovascular function are potentially serious problems.

Many of the other agents are associated with an even higher incidence of side effects than is thiopental. Use of diazepam may result in a prolonged recovery time; ketamine produces emergence delirium; etomidate is painful on injection and, like minaxalone, is associated with the frequent occurrence of patient movement; propanadid causes cardiovascular depression equal to that of thiopental and has a high incidence of nausea and vomiting. Althesin is a drug of particular interest and popular with some anaesthetists. ${ }^{9}$ However, others feel that the hypersensitivity reactions occasionally associated with Cremophor EI, used as a solubilizer in Althesin, propanidid, diazepam and diisopropyl phenol, makes it difficult to justify the use of these preparations if good alternatives are available.

Fentanyl is another drug valuable in day care surgery units. It may be administered by intermittent bolus injections or continuous infusion ${ }^{10}$ and provides cardiovascular stability, rapid awakening

\section{TABLE Discharge criteria}

- No acute surgical complications (e.g., bleeding from the incision).

- No excessive pain.

- The patient must be awake, oriented in time and space, and feel sufficiently in control of his actions to be discharged.

- Assessment by recovery room staff confirms patient ready for discharge.

- The patient must have acceptable vital signs that have remained stable for a period of time considered appropriate by the anaesthetist.

- The patient must be able to take fluids well.

- The patient must leave in the company of a responsible adult.

- The patient must be aware of the recommendations regarding their activities following discharge, to which their attention was drawn on admission to the day care surgery unit.

and good postoperative analgesia. The incidence of postoperative complications compares favorably with halothane or enflurane when used for outpatient surgery. ${ }^{11-13}$

The merits of inhalation and intravenous techniques of anaesthesia have been debated frequently and each technique offers certain advantages and disadvantages. Inhalation agents are taken up and eliminated rapidly; they potentiate neuromuscular blockade, allow spontaneous breathing and are associated with less nausea and vomiting. Nitrous oxide, fentanyl, relaxant techniques allow rapid awakening as well, cause less cardiovascular depression and fewer arrhythmias and generally provide good postoperative analgesia. Although it is well known that narcotics cause respiratory depression, it should also be kept in mind that even very low levels of the potent, inhalation agents will also depress the patient's response to hypercarbia and hypoxaemia. ${ }^{14-16}$

The recovery of day care surgery patients from general anaesthesia is managed in the same manner as for inpatients but discharge criteria are different because instead of retuming to the horizontal position in another part of the hospital with skilled assistance available, they must assume a vertical posture and make their way home.

The basic problem is "What are the criteria for an appropriate ambulatory state?" These have never been defined and opinions between institutions vary somewhat. Another problem is "What specific tests can be done to test a patient's suitability for discharge?" Many exist, but there is no single 
comprehensive test for clinical use. Tests requiring laboratory equipment are too complex to be used routinely ${ }^{17}$ and patients cannot always assess their own capability accurately.

Our own guidelines for preparation and completion of discharge from the day care surgery unit are summarized in the Table.

\section{References}

1 Chen $L H$, Watkins $M L$. Anti-emetic premedication in out-patient anesthesia. Anesthesiology 1981; 55: A280.

2 Rita L, Goodarzi M, Seleny $F$. Effect of low dose droperidol on postoperative vomiting in children Can Anaesth Soc J 1981; 28: 259-62.

3 Azar I, Lear E, Arismendy C. Psychomotor function following balanced, enflurane and isoflurane anesthesia in ambulatory surgical patients. Anesthesiology 1982; 57: A340.

4 Azar I, Karambelker MD, Lear E. The arousal state and incidence of abnormal neurological signs during recovery from balanced anesthesia, enflurane, and isoflurane. Anesthesiology 1982; 57: A343.

5 Aldrete JA, Lowe HJ, Virtue RW. Low flow and closed circuit anaesthesia. Grune and Stratton, 1979.

6 Clarke RSJ. Comparative merits of intravenous anesthetic agents for outpatient surgery. Intemational Anesthesiology Clinics 1982; 20: 51-69.

7 Kenry GNC. Alternatives to Inhalation Anaesthesia. Br J Anaesth 1981; 53: 755-805.

8 Jenson S, Schou-Olesen A, Huttel MS. Use of midazolam as an induction agent: Comparison with thiopentone. Br J Anaesth 1982; 54: 605-7.

9 Towler CM, Garnett RT, Sear GW. Althesin infusions for maintenance of anesthesia. Anaesthesia 1982; 37: 428.

10 White $P F$. Continuous infusion vs, intermittent bolus administration of fentanyl or ketamine for outpatient anesthesia. Anesthesiology 1982; 57: A329.

11 Purdell-Lewis JG, Blair DM, McLeod CA. Studies in fentanyl-supplemented anesthesia: Awareness and effect of naloxone on early postoperative recovery. Can Anaesth Soc J 1981; 28: 57-61.

12 Chen $L H$, Berman $M L$. Fentanyl vs. enflurane in outpatient anesthesia. Anesthesiology 1979; 51 : 551.

13 Dhamee MS, Gandhi SK, Callen KM, Kalbfleisch $J H$. Morbidity after outpatient anesthesia - A com. parison of different endotracheal anesthetic techniques for laparoscopy. Anesthesiology 1982; 57 : A375.

14 Knill RL. Gelb AW. Ventilatory responses to hypoxia and hypercapnia during halothane sedation and anesthesia in man. Anesthesiology 1978; 49: 244.

15 Knill RL, Manninen PH, Clement $J L$. Ventilation and chemo-reflexes during enflurane sedation and anaesthesia in man. Can Anaesth Soc J 1979; 26: $353-60$.

16 Knill RL, Clement $J L$. Variable effects of anaesthetics on the ventilatory response to hypoxemia in Man. Can Anaesth Soc J 1982; 29: 93-9.

17 Editorial: Recovery from anaesthesia. Anesthesiology $1975 ; 43: 285$. 